\title{
Values in Life Domains in a Cross-National Perspective
}

\author{
Loek Halman · John Gelissen
}

Published online: 30 April 2019

(C) The Author(s) 2019

\begin{abstract}
The increase in international survey research projects investigating basic orientations reveals that the grand sociological theories fall short in explaining the often large differences between populations in contemporary societies that continue to exist. There is more than modernization to explain varieties. Institutions, culture, history, policies, all appear to affect people's values. Our review of current stateof-the-art cross-national research activities demonstrates that increasingly multilevel analysis techniques are applied to address either modernization or institutionalism, or both. From various theoretical perspectives, hypotheses are extracted about the impact of the context on values in a specific domain. The selected studies include very different contextual features to explain varieties in domain-specific value orientations, which clearly proves that there are different mechanisms at work in the distinct value domains. The studies reveal that "context matters," but also that it essential to include individual-level characteristics, at least as controls. Quite often, the individual attributes appear differently distributed in different countries, which may be the main reason why differences in value orientations between countries remain.
\end{abstract}

Keywords Moral beliefs · Europe · Modernization · Institutionalism · Multilevel · Micro and macro effects

L. Halman $(\bowtie) \cdot$ J. Gelissen

Department of Methodology and Statistics, TS Social and Behavioral Sciences, Tilburg University

Warandelaan 2, PO Box 90153, 5037 AB Tilburg, The Netherlands

E-Mail: loek.halman@uvt.nl

J. Gelissen

E-Mail: J.P.T.M.Gelissen@uvt.nl 


\section{Werte in unterschiedlichen Lebensbereichen in einer ländervergleichenden Bestandsaufnahme}

Zusammenfassung Die Zunahme an internationalen Umfrageforschungsprojekten, die grundlegende Wertorientierungen untersuchen, zeigt, dass die großen soziologischen Theorien nicht ausreichen, um die oft großen Unterschiede zwischen den Bevölkerungen in heutigen Gesellschaften zu erklären. Es gibt mehr als nur Modernisierung, um die Unterschiede zu erklären. Institutionen, Kultur, Geschichte und Politik scheinen alle die Werte der Menschen zu beeinflussen. Die vorliegende Überprüfung der aktuellen internationalen länderübergreifenden Forschungsaktivitäten zeigt, dass zunehmend Mehrebenenanalysen verwendet werden, um entweder Modernisierung oder Institutionalismus oder beide theoretischen Ansätze gemeinsam zu untersuchen. Aus verschiedenen theoretischen Perspektiven werden Hypothesen über die Auswirkungen des Kontexts auf Werte in einem bestimmten Lebensbereich generiert. Die ausgewählten Studien untersuchen sehr unterschiedliche kontextuelle Merkmale, um die Varianz domänenspezifischer Wertorientierungen zu erklären, was eindeutig belegt, dass unterschiedliche Mechanismen in den verschiedenen Lebensbereichen wirken. Die Studien zeigen, dass „Kontext“ von Bedeutung ist, aber auch, dass es notwendig ist, Merkmale auf individueller Ebene zu berücksichtigen, zumindest als Kontrollvariablen. Häufig sind die individuellen Merkmale in den verschiedenen Ländern unterschiedlich verteilt, was der Hauptgrund dafür sein kann, dass Unterschiede in den Wertorientierungen zwischen den Ländern bestehen.

Schlüsselwörter Moralvorstellungen · Europa $\cdot$ Modernisierung · Institutionalismus · Multilevel · Mikro- und Makroeffekte

\section{Introduction}

This paper takes us on a journey into some recent empirical studies on moral and religious beliefs, political views, family and gender issues, and work values. All of these regard people's values to result from influences of characteristics of the national context in which people live and of their sociological background characteristics. Efforts have been made in recent years to test theoretically informed hypotheses about micro and macro effects on values, and combining micro- and macro-level determinants has become the benchmark in many sociological studies, most of which focus on one or more specific domain or domains of values.

Although there have been attempts to find overarching value systems covering values in all life spheres, most studies show that modern society appears to be highly fragmented regarding its fundamental social values. The various value domains do not constitute clear patterns of values: Values appear domain specific (Halman and de Moor 1987, 1994; Kerkhofs 1997). This finding is not surprising. Some authors have argued that due to modernization processes such as differentiation and specialization, life domains have become independent sectors in society with their own values and independent of religion (Durkheim 1964; see also Smelser 1973; Meulemann 1983). 
Because value patterns appear fragmented, value domains can be explored separately, which is something that we will be doing in this paper. We focus on orientations regarding morality, religion, relationships, politics, and work. The selected studies regard values as consequences of individual and macro features, and test related theoretically informed hypotheses using state-of-the-art multilevel models (Fox 2016; Hox et al. 2017). In particular, all selected studies use random intercept models or-if cross-level interaction hypotheses are considered-random interceptand-slopes models to investigate the complex interplay between macro-level and individual-level determinants of values. The data analytical design of the studies that we discuss takes the country level as the macro level, although we also include studies that additionally — or rather alternatively — consider lower-level regional contextual effects rather than, or in addition to, country-level effects (see also Meuleman and Gorres, Siewert and Wagemann in this volume). The studies demonstrate that there is more than modernization, understood as economic advancement, to explain differences in values, and that institutions are significant determinants of values as well.

Before we present the studies, we start this paper with a brief discussion of the modernization perspective, followed by a reflection on some of the methodological issues that studies on explaining country differences in value domains have to cope with.

\section{Theoretical and Methodological Perspectives}

\subsection{Modernization Theory}

Survey projects, such as the European Values Study (EVS) and World Values Surveys (WVS), European Social Survey (ESS), and the International Social Survey Programme (ISSP), reveal significant similarities but above all dissimilarities in values across European countries. Attempts to understand the variation in basic value orientations often refer to modernization theory. The central claim of this theory is that socioeconomic development goes hand in hand with coherent and-to some extent-predictable societal changes (Marsh 2014). A second common element is that less developed societies acquire characteristics that are common to more developed societies (e.g., Lerner 1968, p. 386). Thus, "if and as the level of modernization increases, the level of structural uniformity among relatively modernized societies continually increases" (Marsh 2014, p. 279). This would imply that pre-modern and modern societies differ from each other much more than do the many varieties of modern society (Schmidt 2010, p. 516). Hence, convergence in values is to be expected.

The claims of modernization theory have been contested and refuted. For example, Gundelach (1994) found that institutional factors appeared to constitute far better explanations of variations in basic orientations than economic development did. Proponents of modernization theory defend their theory by stating that modernization is not deterministic but probabilistic. Socio-economic development seems to bring predictable cultural and political changes, and economic collapse tends 
to bring predictable changes in the opposite direction (Inglehart and Welzel 2005, p. 20). However, the idea that modernity as it has developed in the Western world will be taken over in all modernizing societies should be qualified. Modern societies may have many features in common, but differences persist between them regarding mentalities, institutions, and other factors (Sachsenmaier 2002, p. 42). This naturally resembles the idea of path dependency. Although societies seem to develop in similar and predictable directions, the actual trajectory is dependent on historical backgrounds, persisting traditions, and other country-specific factors (Inglehart and Welzel 2005, pp. 19, 20). Modernization is taking place all over the world, but in different shapes and very specific and unique ways. There is no single version of modernization (Preyer and Sussman 2016, p. 10; Eisenstadt 2002).

\subsection{Within-Country Variation}

Studies that analyze values in different countries confirm the ideas of multiple modernities. The Atlas of European Values (Halman et al. 2011) reveals that Europe is far from homogeneous on many issues, and that country differences seem to persist. Inglehart's (2018) cultural map of the world also provides evidence for rejecting the idea of convergence in orientations.

Countries' positions are, however, inferred on such maps from the countries' means calculated from individuals' values. In doing so, it is neglected that countries can have the same mean value for a characteristic, but differ considerably in the variance of the characteristic. Societies with similar means on a specific orientation can be homogeneous, but also very heterogeneous. Within-country distributions should therefore not be overlooked.

Taking into account distributions within countries is also important because countries may differ significantly in the composition of important individual-level explanatory variables. If such characteristics are distributed unevenly across countries, then such compositional differences may explain not only differences between individuals, but also differences between countries (Diez-Roux 2002). Such composition effects are often not controlled for in aggregate-level analyses.

Investigating relationships between macro-level characteristics of societies often results in high percentages of explained variances in value orientations. However, Robinson's (1950) article on "ecological fallacy" made it clear that one should avoid making inferences about individual behavior from aggregate data because strong associations between macro characteristics cannot necessarily be generalized to lower levels. It can therefore be highly misleading to investigate value patterns and their changes at the macro level only, and expect similar associations to occur at the individual level. One cannot fully understand the internal logic of societies or cultures in the terms used for individuals' personality dynamics. Coleman's (1990) famous "boat" illustrates the complex connections between the micro and macro levels. As Coleman showed, associations can exist between variables at the macro level because such variables either relate directly to each other or because a macrolevel variable exerts an influence on another macro-level variable via mechanisms that run via individual-level characteristics, or both. 
It is obvious that people do not live in isolation, but in a context which constrains or stimulates, and, as such, the cultural and social climate in a society codetermines people's attitudes, values, and behaviors. People adjust to what they experience and what other people around them are doing. Thus, despite individualization and increased levels of personal autonomy in modern societies, individuals are not entirely free but constrained, not only by their context, but also by the way in which they are raised and socialized. Parents, relatives, friends, and peer groups mold and determine people's feelings, ideas, beliefs, and values.

Individuals are naturally not deterministic victims of social pressure and circumstances, but such factors make it more likely that specific outcomes for these individuals will occur. People carry around in their heads a basic stock of knowledge that is the result of living in a particular country, culture, or subculture, but they do not mechanically respond to external stimuli. People have an inner mental life and highly subjective experiences. People's actions, attitudes, and values are therefore a joint product of individuals' needs, traits, temperament, culture, socialization, and personal experiences (Mead 1934). Institutions, the social context, and history all play a role, though it is the individual who makes the final decision in the end. People's responses can be in line with these norms, but they can also deviate from the group's standards. To investigate this, a multilevel approach is needed in which both levels-individual features and context characteristics-are accounted for simultaneously.

\subsection{Addressing Multilevel Issues}

The recent increase in international comparative (survey) data sources, together with the rapid development of advanced statistical methods to analyze micro and macro levels simultaneously, enable researchers to address these multilevel issues. No wonder, then, that numerous articles and papers have appeared in scientific journals and at conferences investigating research problems combining micro-level with macro-level explanations of sociological phenomena.

The idea that both individual features and context characteristics influence people's values and actions is of course far from new in the sociological discipline. What is, however, somewhat of a recent development is that sociologists use the possibility to investigate micro and macro determinants simultaneously. Before the advent of multilevel statistical modeling, analyses combining micro and macro features were often done country by country. The effects of individual characteristics were investigated for each country separately, and compared with the effects that such characteristics had within other countries. Such a country-specific approach was applied in The Civic Culture (Almond and Verba 1965) to examine whether or not effects were similar, or whether different effects were reported country by country in countries with different political-historical experiences and findings.

Country-by-country analyses were also presented in more contemporary works. Inglehart (1977) confirmed his theory of The Silent Revolution by testing his hypotheses in each of the selected countries separately and in Political Action (Barnes and Kaase 1979), five Western democracies were analyzed separately to explore the political action repertoires and their antecedents. A repeat study was carried out in 
a more limited number of countries, also including country characteristics, testing the expectation that "the process of modernization will lead to more or less similar individual responses of the people in these societies" (Van Deth and Jennings 1989, p. 17). And although the contributors to the volume edited by Van Deth and Scarbrough on the Impact of Values (1995) applied somewhat more sophisticated statistical methods, they organized and presented their analyses country by country.

An early attempt to investigate context effects was made by De Moor (1987) in analyzing the European Values Study data on religion and morality. Country dummies were included in regression analyses in order to explain individual differences in religious and moral values. It appeared that the country in which people live does indeed have an effect, but which country attribute or attributes causes this effect remained unclear because country dummies do not reveal what country-level factor has an effect. Referring to countries without defining or clarifying what country features explain differences adds virtually no new information to the observation that there appear to be differences across people in different countries. The problem is, however, that it has hardly been thoroughly theorized what these features are or can be. As such, notions such as country, nation, and state are merely "black boxes" hiding many features, which might and will be important (see Kroneberg 2019 in this special issue).

The enormous amount of (survey) data available to social scientists these days makes it painfully clear that there is a problem of how to cope with all the varieties and similarities, and how to interpret and explain them. The grand theories of modernization appear far too general to explain the variations that exist between populations in different countries. De Moor (1994, p. 232) therefore concluded that "empirically founded partial theories are needed." The challenge for contemporary comparative sociology is to develop theories to understand and explain how similarities and differences at the macro-level lead to micro-level differences and similarities.

Value researchers should test such theories by replacing country dummies with precisely defined country characteristics (Przeworski and Teune 1970), but even then ordinary OLS (ordinary least squares) regression analyses risk overestimating the significance of country effects (i.e., they provide too liberal a test) because calculations are based on the numbers of individual cases and not on the number of countries. To limit the risk that one too quickly concludes that "context characteristics matter," multilevel analysis techniques should be applied, and these have become standard practice in contemporary sociological journals to investigate multilevel issues. It means that theories are developed to elaborate mechanisms for effects at both levels and sometimes combine both levels and extract cross-level interactions from these theories to explain that individual-level effects may be different in certain contexts/circumstances.

\section{Making Sense of the Variety in Values}

We selected studies for inclusion in this contribution that were conducted in the domains of morality, religion, politics, family, and work which explored the im- 
pact of both individual and macro characteristics and applied multilevel analyses to understand and explain the value differences and similarities in European countries.

\subsection{Moral Views: Personal and Civic Morality}

Several empirical studies on moral views which rely on survey data from the European Values Study distinguish between two moral dimensions "personal morality" and "civic morality." The first refers to relational or interpersonal behaviors and sexual conduct, whereas the second deals with minor cheating or dishonesty or petty fiddling and activities which contravene the law (see e.g., Phillips and Harding 1985; De Moor 1987; Halman 1991; Halman and Vloet 1994; see Table 1).

Letki (2006) explored civic morality, i.e., compliance with the law and public order or respect of and obedience to the norms and rules. She formulated hypotheses about the effects of individual levels of trust, regional levels of social capital, and macro or country levels of institutional configurations (Letki 2006, p. 311), and analyzed data from WVS in 38 countries. The quality of a country's government, which was measured by government effectiveness, regulatory quality, the rule of law, and control of corruption (from the World Bank Governance Indicators Dataset), and economic performance (Gross Domestic Product (GDP) growth and level of unemployment; Letki 2006, p. 321) appeared to be important attributes. At the individual level, determinants of civic morality are socio-economic characteristics, but the hypothesized effects of generalized trust and the vibrancy of associational life, indicating regional levels of social capital, were not confirmed. The finding that "the dimensions of institutional quality which are relevant to ordinary people's lives, to competence and transparency as well as to the efficiency of the civil service, the level of contract enforcement, the incidence of corruption, levels of crime and the level of unemployment" (Letki 2006, p. 321) affect civic morality is groundbreaking, since researchers often measure institutional quality by general variables such as GDP growth or the level of democracy. Such findings reveal that the institutional context matters for people's attitudes towards compliance.

Apart from hypothesizing that more highly religious people will hold more conservative views on morality (see Siegers 2019 in this special issue), Finke and Adamczyk (2008) also explored the effect of religiosity at the macro level, arguing that morality will be stronger in more religious nations (Finke and Adamczyk 2008, p. 619). They also formulated a cross-level interaction hypothesis, holding that the impact of an individual's religiosity will be stronger in more religious contexts, and they additionally expected differential effects of religiosity for different kinds of morality, with effects being strongest for moral issues which are not sanctioned by the state. They relied for the analyses on ISSP and WVS data, and their measures of morality correspond to the dimensions that had been distinguished earlier by Stoetzel (1983) and by Phillips and Harding (1985): Morality that is sanctioned by legal codes and morality that is not sanctioned by the state. At the country level, they included both an aggregated measure of the combination of church attendance and religious importance in ISSP, and other variables such as religious concentration (Herfindahl index), migration, corruption, dominant religion, and homosexuality regulation. At the individual level, religiosity was not measured by church attendance alone, but 


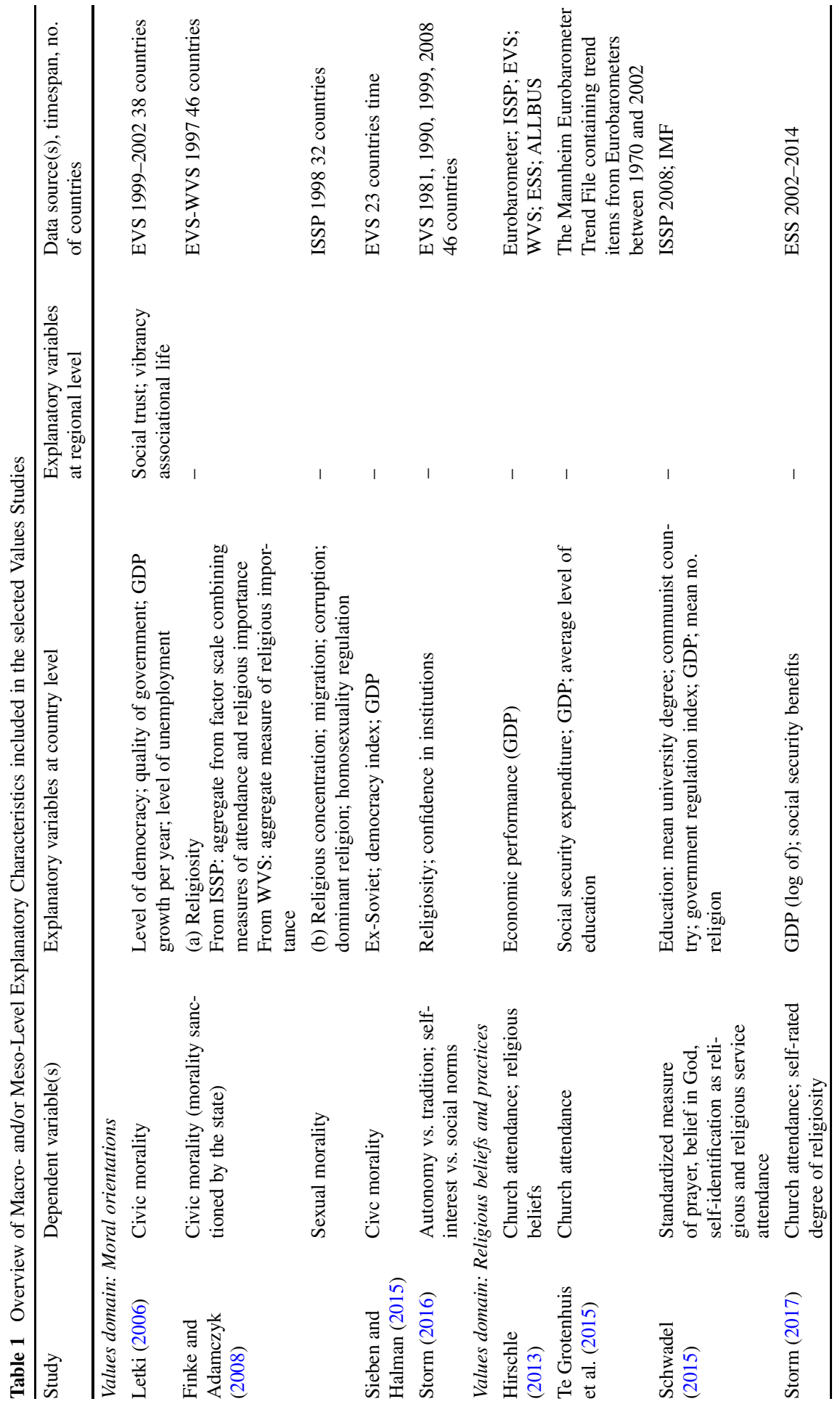




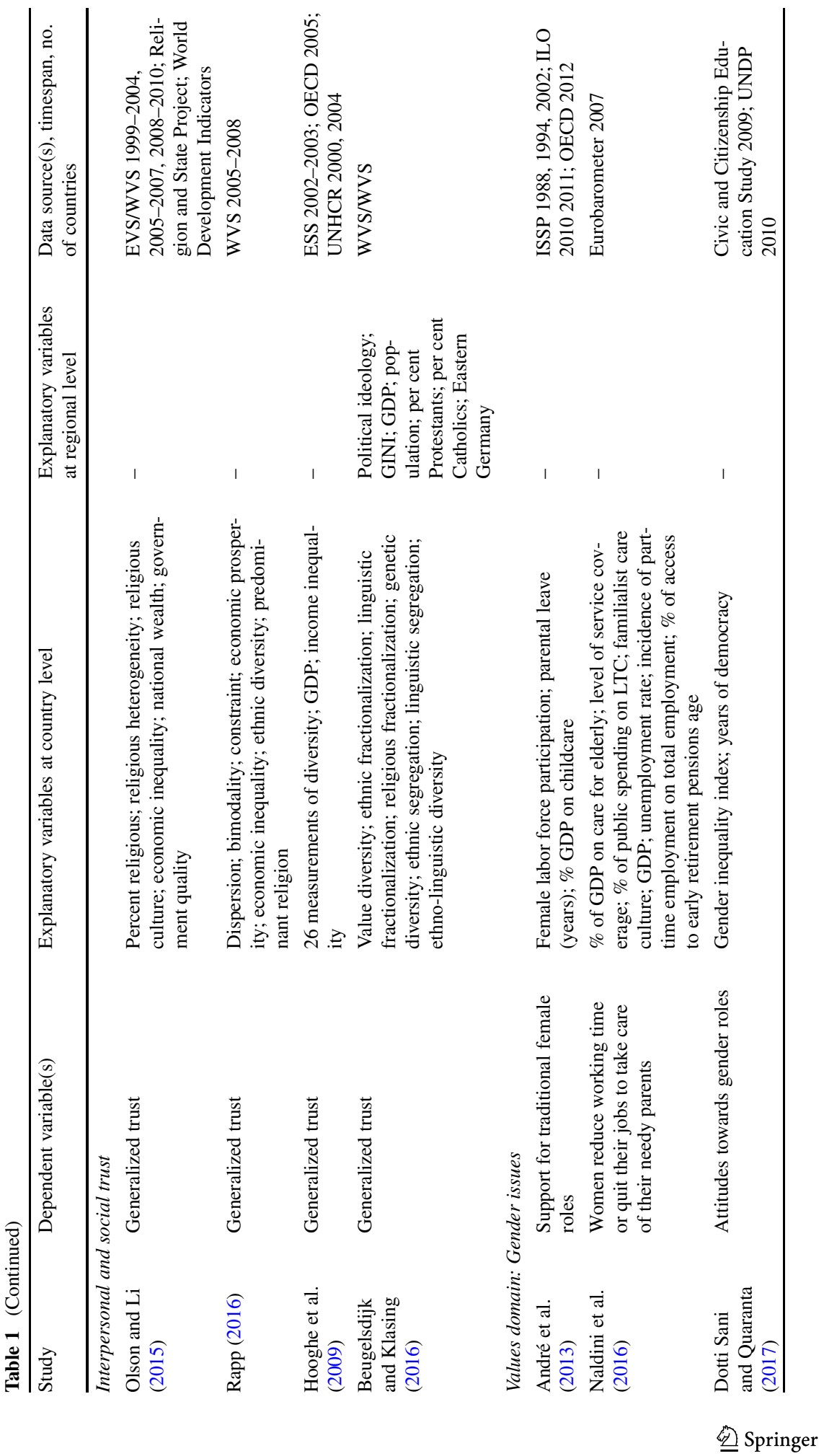




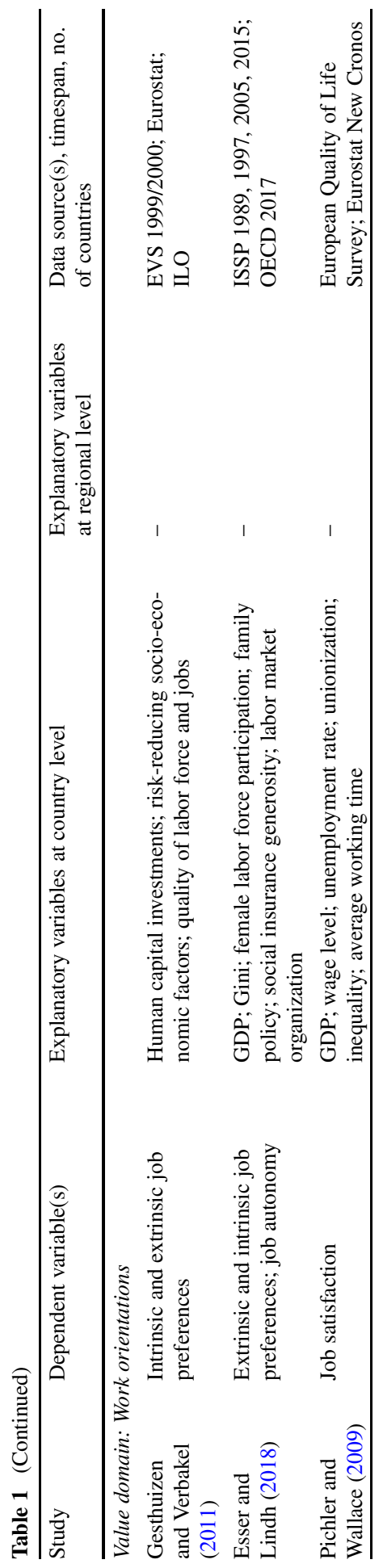


also by personal religious beliefs, while denomination was included as a control variable, in just the same way as marital status, gender, age, and education. Their multilevel analyses show that the religious context matters, as do a person's age and religious beliefs and practices, at least in the case of moral issues not sanctioned by the state. Context and individual-level features do not have much explanatory power for moral issues which are sanctioned by legal codes.

Sieben and Halman (2015) also addressed public good morality. Their interest was the impact of the communist legacy on the justification of issues which are defined as illegal. They focused on post-socialist Europe, and found differences between individuals and countries in the degree to which behaviors that harm the public good are considered justified. They expected that the experience of repressive communist rule would induce lower levels of public good morality, which would be the case for people who had lived under communist rule for a prolonged period. This hypothesis is only partly confirmed, and, remarkably, the younger inhabitants of that part of Europe appear to be the most lenient on public morality issues. They found no support for the expectation that the process of democratization results in higher levels of public good morality and that individuals would be stricter as they would endorse democratic values more strongly.

Storm (2016) investigated the relationship between religiosity and moral values in a secularizing Europe longitudinally, using the data from the EVS waves in 1981, 1990, 1999, and 2008. Next to civic morality, or morality sanctioned by the state, she also addresses morality "that is not uniformly sanctioned by legal codes" (see Finke and Adamczyk 2008, p. 622) and for which religion often appears to be a better predictor than it is for state-sanctioned civic morality (Storm 2016, p. 113). She also formulated hypotheses about generational value change, the differential impact of countries' levels of religiosity on the two moral dimensions, and about the dependency of these moral orientations on weak or illegitimate governing institutions. The religious context, measured by the average level of religiosity in a country, matters, especially for religious people. The religious context matters, which supports the social network hypothesis of Putnam and Campbell (2010) "that the availability of religious fellow citizens increases the impact of religiosity on moral values" (Storm 2016, p. 133). The evidence that she found once again demonstrates the importance of context for explaining differences in moral views in Europe.

\subsection{Religious Beliefs and Practices}

Davie's (1994) striking characterization of the British religious situation in the early nineties echoed Durkheim (2001 [1912]) that religion is about beliefs and practices. She described Britain's religious situation as "believing without belonging," meaning that, as in many European countries, church attendance is on the decline, but religious beliefs (i.e., individuals' levels of religiosity) seem to persist.

Economic development is considered to be one of the leading causes of this situation. Inglehart (1997) contended that due to increasing levels of economic security, indicated by, for instance, GDP or related measures such as social security expenditures, people no longer need the church for salvation and reassurance (Inglehart 1997, p. 80; Norris and Inglehart 2004, p. 18). It does not imply that religiosity 
as such is declining, but that the once dominant role of the churches is gradually diminishing.

That is also what was found by Hirschle (2013), who investigated the impact of economic growth on church attendance and religious beliefs. Based on the classic secularization idea that economic growth leads to disenchantment and to increasing levels of existential security, he expected a decline in religious values, resulting in turn in a drop in church attendance (Hirschle 2013, p. 412). The alternative explanation was that, with economic growth, people's needs are increasingly satisfied by secular goods and less by religious products. Hence, one can expect a decline in church attendance, leading in turn to a decline in religious beliefs, because the churches lose their socializing capacity. Using data from ISSP, EVS, WVS, ESS, and ALLBUS, he found that an increase in GDP is associated with declining church attendance, while religious values persist. When economic growth is considered as "a proxy for the expansion of a market for alternative goods that meet religious needs" (Hirschle 2013, p. 422), the alternative explanation is presumably substantiated.

Hirschle's contribution concerned the macro level only. Te Grotenhuis et al. (2015) considered both macro- and individual-level explanations. Like Hirschle, they argued that higher levels of wealth and security, both at the individual and the country level, will be conducive to lower levels of church attendance (2015, p. 644). Increasing rationalization, and hence higher levels of education, will also undermine traditional religious worldviews, both at the individual and the country level. Finally, when social ties are weak and heterogeneous (as is the case in urbanized areas), the normative pressure to conform to the environment is weaker and social control less severe. Analyzing the Mannheim Eurobarometer Trend File (GESIS Datenarchiv, Köln. ZA3521 Datenfile Version 2.0.1), they found that it was rising levels of GDP that reduce church attendance and not social security expenditures or rising levels of education and urbanization. This conclusion does not hold for individual levels of wealth and security. Hence, the context appears to matter more than the individual level of income, education, and urbanization.

The importance of the context is also demonstrated by Schwadel (2015), who elaborated on the effect of education on religiosity and found that national context mitigates the effect of education. Although he also argued that a higher level of schooling should negatively relate to religiosity at both individual and macro levels, he also expected that this association would differ across countries: Any negative effect will be strongest in (former) communist and religious countries, and weak(er) in highly educated countries. Analyzing ISSP 2008, he concluded that an individual's education has the predicted effect, although sex, marital status, and age appear to have stronger effects on religiosity (Schwadel 2015, p. 414). A national effect of education, which was "assessed with the mean of the university degree variable in each nation" (Schwadel 2015, p. 407) is not confirmed, but GDP, included as a control variable, appeared to fully mediate the association between nation-level education and individual religiosity. He also found support for the hypothesis that the schooling effect varies across countries, but he could not substantiate the hypothesis that the association will be strongest in (ex-)communist countries for which he created a dummy variable and in more highly-educated countries. He finds support, 
however, for the hypothesis that the effect of education is strongest in more religious countries. Schwadel measured the level of religiosity in a nation with "the mean with no religious affiliation (...), standardized to adjust for the positive skew" (Schwadel 2015 , p. 407). Once again, the results demonstrate that the context matters, and above all that the context may moderate the effect of individual characteristics, in this case the level of education. Also, the importance of GDP in this analysis underscores the idea that existential security is an important driver of secularization. Government regulation of religion, for which Schwadel relied on Grim and Finke's (2006, p. 7) Government Regulation Index assessing "restrictions placed on the practice, profession, or selection of religion by the official laws, policies, or administrative actions of the state," was also included as a control variable because it should affect religiosity negatively, but the effect was negligible.

Storm (2017) explored the effects of GDP and economic security on self-rated degrees of religiosity and tested several individual-level and macro-level hypotheses. In the same way as Hirschle, she distinguished attending religious services from religious beliefs, and expected that these would differentially associate with existential security issues. She hypothesized first that individual and national economic prosperity would negatively relate to religiosity. Second, she conjectured that social protection expenditures would negatively impact on the individual's religious participation because social protection is an alternative to religion in providing security. When religion is considered a buffer or substitute in stress situations, the church as a faith community may offer comfort and support, but one may also find comfort and meaning in religious beliefs and worldviews. Hence, Storm expected that religious people would evaluate their financial situation more positively than less religious or nonreligious people. Finally, she tested the well-known hypothesis that economic growth leads to a decline in religiosity. She used GDP for economic prosperity, and welfare expenditure was measured with the percentage of GDP spent on social benefits.

Storm's analysis of ESS data covering the years 2002-2014 showed that individual and macro levels of prosperity are indeed associated with lower levels of church attendance and self-rated religiosity, but that over time, changes in GDP do not explain the religious changes. Her religious substitution hypothesis was confirmed only for church attendance, but not for self-rated religiosity.

All in all, these studies show that distinguishing religious beliefs from practices makes sense, and that it is not only macro-level factors that determine levels of religiosity; religious orientations are also determined to a considerable extent by individual characteristics which studies on secularization and religious change should not ignore.

\subsection{Political Values: Generalized and Social Trust}

Classical political values refer to security, order, respect for authority, and conformity, whereas more contemporary values stress personal autonomy, independence, and emancipation (Van Deth 1995, p. 2; Inglehart 1997; Halman 2007). Some political values may turn out to be more persistent than others, and have not vanished. For example, in The Civic Culture (Almond and Verba 1965), several democratic 
attitudes were distinguished that were already identified as important by de Tocqueville, and that are considered (again or still) highly relevant today. Such attitudes of trust, political partisanship, and societal involvement are vital concepts of what the sociological literature recognizes as social capital, a notion that has regained prominence since the works of, for instance, Putnam (1993) and Fukuyama (1995). Here, we will survey publications on interpersonal or social trust, which is considered a fundamental orientation for democracies. Numerous studies have addressed the impact of diversity on generalized or social trust, and we selected a few of them.

We know a lot about the greater trust that religious people have, but we know less about the effect of a religious setting on trust among both religious and nonreligious people. Olson and Li (2015) measured religious context not only as the percentage of the population that is religious, but also as the heterogeneity of religious groups among religious people measured by the well-known and commonly used Herfindahl index (Olson and Li 2015, p. 757). They expected that "because religious people are likely more engaged in trustworthy and trust-fostering interactions" (Olson and Li 2015, p. 758), the more people in a country are religious, the higher the level of trust will be. From religious heterogeneity theory (see Siegers' 2019 in this special issue), they predicted that a more diverse religious landscape emphasizes religious differences and creates boundaries between religious groups. Hence, levels of mistrust will be lower in homogeneously religious societies. Their study is innovative in that they argued about the combined effect of these two context characteristics. The interaction hypothesis that they formulated was that an increase in religious heterogeneity makes the predicted positive effects of percent religious less positive. "Increases in the percent religious make the negative predicted effects of religious heterogeneity on trust even more negative" (Olson and Li 2015, p. 760). The study included individual-level variables such as church attendance and religious tradition as controls for compositional differences between countries.

The results showed that religious context indicators did not affect trust, but also that, when combined, there is a substantial effect as predicted in their hypothesis that: "Nations that are both highly religious and religiously heterogeneous have much lower levels of trust" (Olson and Li 2015, p. 769). This finding is all the more interesting since it contradicts what is usually found, and confirmed in Olson and Li's study, namely that religious people usually appear more trusting than nonreligious people. This result underscores the fact that individual-level effects can differ from macro-level effects, hence the need to include both levels in the analyses.

Also, Rapp (2016) included characteristics at both levels in testing the hypothesis that levels of trust are lower in more morally polarized societies. Her study captured opinion polarization in three ways: "dispersion, bimodality, as well as issue constraint between our three moral issues of homosexuality, abortion, and euthanasia" (Rapp 2016, p. 37). Rapp based her hypothesis on the idea of perceived similarity: People tend to associate more, feel more comfortable with, and put more trust in those whom they perceive as similar. Rapp explores this idea for moral opinions, arguing that people trust each other less in morally more polarized societies. Analyses of the 2005-2008 WVS data confirmed the negative relationship between moral opinion polarization and social trust. Having said that, the individual-level characteristics also had significant effects on an individual's trust, demonstrating 
the necessity to not only rely on macro-level analyses, but also to control for such compositional effects.

Diversity was the primary concern of Hooghe et al. (2009). They explored the impact of no fewer than 26 measures of diversity regarding immigration, ranging from the well-known and often applied fractionalization index taken from Alesina and La Ferrara (2002) to the inflow of foreign workers to asylum requests, for which they relied on OECD figures (Alesina and La Ferrara 2002, p. 219). Apart from such country characteristics, they also included individual-level variables as controls. Analyses of these control variables substantiated other studies, but the expected country-level effects were not confirmed. Their key hypothesis was based on the perceived threat thesis, and stated "that the population of the host society will be less trusting when it faces a rapid rise in the immigrant population over time and when the perceived cultural and religious distance or economic differences between immigrants and the majority group are larger" (Alesina and La Ferrara 2002 , p. 204). This hypothesis found no support; hence the often-assumed negative impact of ethnic diversity on generalized trust does not hold in Europe (Alesina and La Ferrara 2002, p. 218).

To explore diversity's presumed impact on trust, Beugelsdijk and Klasing (2016) focused on the role of shared values or "conversely, the degree to which society is polarised along such values" (Beugelsdijk and Klasing 2016, p. 524). They calculated the degree of value polarization for 17 questions in EVS-WVS, and took the averages across these 17 scores for each country and wave to calculate the degree of value diversity (Beugelsdijk and Klasing 2016, p. 526). Using arguments from social identity theory, they verified the idea that value diversity negatively affects generalized trust. It is worth noting that they analyzed at three levels, with individuals being nested not only in countries, but also in regions. Their analyses confirm the expectation that value diversity, especially concerning government intervention in markets and income redistribution, induces lower levels of trust. "This relationship holds at various levels of aggregation: the country level, the sub-national (regional) level, and the individual level" (Beugelsdijk and Klasing 2016, p. 538).

These studies on generalized trust yield mixed results. Cultural diversity appears to affect trust negatively, whereas ethnic diversity does not seem to have much impact on trust. Perhaps the latter did not have much effect because the nation as the context may be too abstract and too distant to affect people in their daily lives; the region and its characteristics may come closer to people's experiences and determine their possibilities and ultimate choices. Beugelsdijk and Klasing show the usefulness of including the sub-national level in the analyses of social or generalized trust.

\subsection{Family and Gender Division of Tasks}

The domain of family life has changed fundamentally in recent years, and a concept such as family "is becoming more fluid and changeable" (Chambers 2012, p. 1). Demographic developments are seen as a consequence of progressing individualization (Lesthaeghe 2014), and changes in family life, primary relationships, and parenthood are regarded as expressions of the growing emphasis placed on personal autonomy, self-expression, and emancipation. The domain of family life includes 
many issues ranging from personal relationships and family types to gender roles and gender equality, adulthood, and same-sex intimacies (see Hank et al. 2019 and Grunow 2019 in this special issue). This variety of topics appears for instance in the 2012 ISSP module "Family and Changing Gender Roles." Apart from attitudes and behaviors on female employment over the life cycle, the successive ISSP modules address attitudes towards marriage, the way a partnership organizes income, the gendered division of household chores, preferred and actual division of paid and unpaid labor, and alternative family forms (www.issp.org). Gender roles, gender equality, and combining work and family life are topical issues in modern societies and national and European policies. Equality between men and women is considered a fundamental human right and is defined as one of the Sustainable Development Goals by the United Nations. Despite progress, gender gaps appear to persist in Europe, albeit to different degrees. The empowerment of men and women has been uneven across regions and within countries (EU 2018; ESB 2017; see also Halman et al. 2011). This unevenness is also recognized by scholars who assume that differences in social, economic, and political contexts determine opportunities and constraints, and hence determine to no minor degree the choices that people make and the values to which they adhere on family- and gender-related issues.

Voicu and Constantin (2014) tried to explain European country differences in support of equal gender roles by modernization and institutional theories. In the same way as Inglehart (2018), they argued that modernization is only part of the explanation of differences in values among European populations, with a country's religious traditions and political heritage being major explanations of a country's trajectory. Their analyses of the 44 countries included in 2008 EVS confirmed that not only socio-economic development, but also main religious denomination, the rate of women's employment, and recent past are important for understanding differences in adherence to the traditional gender roles and attitudes towards gender equality on the labor market. Although not explicitly investigated in the article, some individuallevel characteristics, such as religiosity, age, denomination, and gender, which were included as control variables, appear to be important attributes as well.

André et al. (2013) argued that using socialization theory, women would be more directly affected in their roles than men by family policies aiming at combining paid work and family care. As contextual factors, they included female labor market participation, years of parental leave that can be used by both partners together (both found in ILO data), and governmental childcare expenditures for which they included public expenditure on daycare and home help services as a percentage of GDP in 2000. Statistics came from OECD statistics 2012 (André et al. 2013, p. 460). The individual-level data came from 2002 ISSP data in 32 countries, and included women aged 40-60 years in paid work or who had worked in the past, having or having had frail elderly parents in the past ten years. All their individual-level hypotheses were confirmed, meaning that men are more traditional than women, higher-educated people are less traditional compared to the lower educated, employed people are less traditional, and the more children the respondent has, the more he or she supports traditional female roles. The study also found positive evidence for the adolescence hypothesis stating that when someone grows up in a situation where the mother was employed, he or she will be less supportive of the traditional female role. Their 
analyses made it clear that subsidized childcare and enhancing female labor market participation are probably the best means to reduce the gender gap.

Naldini et al. (2016) also investigated female employment. They investigated the impact of the institutional and cultural context on women's decision to reduce working hours or quit their jobs to take care of their needy parents. They focused in particular on the effects of a country's care policies and (intergenerational) family care culture (Naldini et al. 2016, p. 609). Eurobarometer data from 21 European countries were analyzed, and their main conclusion was that when there is limited formal care in a country, women are more eager to reduce or quit their jobs to take care of their frail parent. More women remain in a paid job in countries where formal care is well organized and where societal norms concerning informal help are weak. Indicators for formal care policies were expenditure on care for the elderly, taken from Eurostat. Level of service coverage from the Multilinks database measures the percentage of over-65s receiving home care to the percentage of total public spending on long-term care; cash allowances were calculated as a percentage of total expenditure on long-term care (Naldini et al. 2016, pp. 612-615). Societal norms referred to familial care culture, which combined the proportions of individuals in each country agreeing with four items in the Eurobarometer survey (Naldini et al. 2016, p. 615). Their study revealed the importance of both policies and culture, but also that it is difficult to disentangle the specific influence of each (Naldini et al. 2016, p. 627). At the individual level, it turned out that occupational class, the presence of a partner, and type of caregiver play a role in determining whether women decide to reduce working hours or give up their work.

The advantages of multilevel analysis also appear in the study by Dotti Sani and Quaranta (2017), who investigated attitudes toward gender roles at three distinct levels of analysis. Next to country differences to explain differences in these attitudes, they expected gender differences to co-vary with the socio-economic background of the family of origin (Dotti Sani and Quaranta 2017, p. 31). Based on dependency theory, they expected that more egalitarian views would prevail in countries with higher levels of gender equality (Dotti Sani and Quaranta 2017, p. 32). From social learning theory, they derived hypotheses about gender differences, and the ideas of social diffusion of innovations theory led to hypotheses about the impact of the background of the family of origin and a cross-level interaction hypothesis about the differential impact of the family of origin for sons and daughters (Dotti Sani and Quaranta 2017, p. 33). The authors formulated two additional cross-level interactions about the differential impact of gender and maternal education in countries with higher or lower levels of gender equality (Dotti Sani and Quaranta 2017, p. 33). For gender equality, they included the Gender Inequality Index 2008 developed by UNDP, which "is a summary indicator accounting for gender-based disadvantages in reproductive health, empowerment, and the labor market" (Dotti Sani and Quaranta 2017, p. 34). The individual-level data comes from the International Civic and Citizenship Education Study 2009 (Schulz et al. 2010), containing data from eightgrade students in 36 countries. The analyses yielded evidence of their hypotheses, not only showing that the family of origin plays a determining role in views about gender equality, but also the countries' level of equality. 
Overall, also in this domain, researchers increasingly make use of the opportunity to compare the attitudes and values between different societies and to study the impact of context characteristics. As seen above, there is evidence that differences in social, economic, and political contexts determine a person's opportunities and constraints, and hence the choices that people make and the values to which they adhere.

\subsection{Intrinsic and Extrinsic Work Orientations and Job Satisfaction}

The Meaning of Work (MOW) project that was carried out in the eighties revealed that work is a core aspect of the lives of large majorities of people in the industrialized world. After "family," it is mentioned as the second most important life domain, a finding that is substantiated by the EVS, which has been asking the same question since 1990 (Zanders 1994, p. 133; Halman et al. 2008, pp. 13-18).

People nevertheless have a variety of different reasons for regarding work as so profoundly important. One reason for people to work is to have income. As the MOW International Research Team (1987, p. 250) stated: "the dominant underlying reason why people work is to secure and maintain an income to purchase needed/or desired goods and services." However, people also engage in paid work for other reasons (see also Grunow and Erlinghagen in this volume). A distinction between extrinsic and intrinsic aspects of work has become widely accepted here. Extrinsic or material aspects refer to the economic rewards such as pay and job security, while intrinsic aspects emphasize the importance of autonomy and personal development (e.g., Jutz et al. 2018, p. 100).

Gesthuizen and Verbakel (2011) investigated whether differences between individuals and countries in extrinsic and intrinsic job preferences are attributable to socialization, economic deprivation, and job qualities. They predicted that people in nations that invest heavily in human capital (percentage of GDP spent on acquisition of human resources), that have low risks of economic deprivation (generous welfare states), and have a high-quality labor market (percentage working in first-digit ISO 88 groups 1, 2, and 3), combined with level of autonomy in a job (aggregated from EVS; Gesthuizen and Verbakel 2011, p. 673), will emphasize intrinsic job qualities more and extrinsic job qualities less. At the individual level, they argued that self-development is considered more important by more highly educated people, who therefore endorse intrinsic work qualities. People who suffer from economic deprivation presumably find extrinsic or material job features more important than intrinsic ones, and while those in low-quality jobs will seek satisfaction outside of work, people in high-quality jobs will presumably find satisfaction in work because it provides opportunities for self-development and autonomy, and therefore the latter will emphasize intrinsic job characteristics. Analyses of the EVS 2008 confirmed their hypotheses.

Esser and Lindh (2018) also analyzed both work orientations, using the work modules in ISSP. They explored the developments in the two work orientations between 1989 and 2015 in 19 Western countries. From modernization theory, they deduced hypotheses about the effects of economic development, increasing levels of education, and female labor participation, while the institutional theory about 
welfare states led to hypotheses about the economic inequality within countries, social protection, and labor market regulations (Esser and Lindh 2018, p. 144). Their explanations of differences in work values are also (see Gesthuizen and Verbakel above) based on socialization theory, economic deprivation theory, and work quality. However, they also explored the effect of gendered socialization and a gendered labor market, "with women employed in the (public) care services promoting what is known as dare-rational motivations ..., which would be reflected in stronger intrinsic valuations among women" (Esser and Lindh 2018, p. 145).

At the country level, modernization theory predicts that higher levels of economic development are conducive to placing a stronger emphasis on intrinsic work aspects and weaker emphasis on extrinsic ones. Modernization and institutional theory predict that female workforce participation will induce stronger intrinsic work values and weaker extrinsic ones. Finally, institutional theory predicts that lower income inequality, more generous welfare provisions, gender equality policies, and regulated labor markets lead to stronger intrinsic work values and weaker extrinsic work values (Esser and Lindh 2018, p. 148). Neither contrasting perspective enjoys consistent support, but changes over time can be generally attributed to growing economic development and female labor market participation, thus underpinning the modernization perspective. The institutional perspective-stressing the importance of equality - was confirmed, but the limited effect of social policies was unexpected (Esser and Lindh 2018, p. 164). It was, however, found once more that both work values act in tandem and that both are more important in more unequal societies.

Work orientations are also significant predictors of job satisfaction. If a job has work characteristics that one considers to be important, it is likely that an individual is satisfied with the job. Indeed, "job satisfaction is regarded as the result of some perceived job characteristics including intrinsic and extrinsic rewards ..." which "are seen as strong factors in the experience of work, which heavily influence job satisfaction" (Pichler and Wallace 2009, pp. 536-537). According to Pichler and Wallace, job satisfaction depends on "the particular country a person lives in (...) because of the specific constellation of work, gender, social, and economic relations in a given context" (Pichler and Wallace 2009, p. 535). At the individual level, they investigated the impact of the type of occupation, supervision responsibilities, working hours, and extrinsic and intrinsic work characteristics. Such issues are known to affect job satisfaction, and since countries' composition of these characteristics may vary, differences in job satisfaction may (also) be a by-product of such individual differences (Pichler and Wallace 2009, p. 538). The primary hypotheses were about the effects of country-level institutional factors. They expected job satisfaction to be higher in countries with higher GDP, higher wage levels and shorter working hours, lower levels of unemployment, and higher levels of both equality and unionization (Pichler and Wallace 2009, pp. 538-539). A counter argument was that where unemployment is high, people can also be happy with their jobs because they have a job at all.

The data were from the European Quality of Life Survey in 28 European countries (European Foundation for the Improvement of Living and Working Conditions 2004). The results indicated that individual-level and compositional effects are the strongest predictors of job satisfaction. Objective working conditions (e.g., occu- 
pational level, type of contract, job-related training) are important determinants of job satisfaction, but above all, both intrinsic and extrinsic job qualities promote job satisfaction. Institutional explanations work less well, but average wage differences mainly determine country differences in job satisfaction. The latter provides better explanations than the unemployment rate, the degree of unionization, and inequality (Pichler and Wallace 2009, p. 546).

Such studies signify the importance of both individual and macro levels when it comes to understanding varieties in work values. Equally importantly, they emphasize that alternative theoretical views should be developed to explain varieties in work orientations and job satisfaction.

\section{New Directions}

The increase in the number of international survey research projects investigating basic orientations makes it painfully clear that the grand theories in sociology fall short when it comes to explaining the often considerable differences between populations in various countries. Modernization theories do not tell the whole story, and cannot explain all the variety in these orientations. The central claim of modernization theory that socioeconomic development solely incurs value differences seems obsolete. It is about more than economy, and institutions, culture, history, and policies all help explain the sometimes major differences in fundamental human values.

So, modernization claims are insufficient; other theoretical notions must supplement them, of which institutionalism appears a good candidate. Our review of current state-of-the-art cross-national research activities, summarized in Table 1, makes it clear that many studies indeed focus on either modernization or institutionalism, or both. The studies use various theoretical perspectives to extract hypotheses about the impact of the context on values in a specific domain. They include very different contextual features to explain the varieties in the domain-specific value orientations, which proves that there are different mechanisms at work in the distinct value domains. The studies reveal that "context matters," but also that it is essential to include individual-level characteristics, at least as controls. Quite often, the individual attributes appear differently distributed in different countries, which may be the main reason why societies vary in certain value orientations. Multilevel analysis is the appropriate tool for separating such composition effects from true contextual effects.

Some of the reviewed studies (e.g., Storm 2016; Finke and Adamczyk 2008; Schwadel 2015; André et al. 2013; Naldini et al. 2016; Dotti Sani and Quaranta 2017; Pichler and Wallace 2009) demonstrated the fruitfulness of theorizing and testing hypotheses about cross-level interactions, arguing that individual-level effects depend on the contexts. Sociologists should be challenged to develop theories combining the macro level with the micro level and reflect on how the macro level may influence micro-level effects.

Two of the studies, namely Letki, and Beugelsdijk and Klasing, examined regional differences. Such studies are not only empirically but also theoretically vital, because 
they draw our attention to the fact that various contextual levels offer the structural and institutional contexts that may shape people's values simultaneously. Both the national and regional level provide conditions and more or less stable frames of reference for behaviors and beliefs. National characteristics capture broader structural and institutional influences that will affect every citizen of a country, and in that sense, they are more distal factors influencing people's everyday actions and beliefs. People base their values on the cultural, political, and economic climate in society. Contextual effects resulting from characteristics at the regional level may be narrower in scope and impact, as they are somewhat more closely related to people's immediate surroundings and daily lives. What is happening at the micro level is nearly always embedded in institutionalized social networks at the meso level, such as markets, organizations, and communities (Arts 2011, p. 29). Fortunately, statistical agencies such as Eurostat are increasingly collecting statistics on regional structural characteristics, and these allow for regional analyses. Expanding the country-level studies to include regional-level characteristics as well would mean a first new direction in comparative sociology.

Many studies rely on comparing mean scores of countries or groups of people with specific characteristics to test hypotheses about varieties in values. However, as we have argued before, the same mean may be based on very different frequency distributions. Frequency distributions may be homogeneous or heterogeneous, and when investigating varieties across countries and groups, it can be fruitful to explore this within-country homogeneity/heterogeneity. This approach can also be interesting from a theoretical point of view because hypotheses about the distributions of orientations can be deduced from individualization and globalization ideas, which are considered critical processes of recent and contemporary social change. For example, individualization would mean that people's choices, actions, and orientations are no longer controlled by their social position, but are increasingly based on personal convictions and individual preferences. Apart from that, the individual in (post-)modern society faces a multitude of alternatives because of internationalization, transnationalization, and globalization. The world has become compressed, and the consciousness of the world has intensified tremendously (Robertson 1992, p. 8). Societies are currently interconnected (Genov 2015, p. 205), and people in this "global village" encounter many alternative cultural habits, lifestyles, and modes of conduct. Because individualized people have been liberated from (traditional) controls and constraints, and given that globalization implies that people can choose from the global cultural marketplace, the likelihood that people will choose the same will decline, and hence the heterogeneity of people's value preferences will increase. Value orientations are therefore not only likely to shift away from traditional views towards individualistic values and declining acceptance of traditional authorities, these orientations and opinions are also likely to become more diverse.

Of course, there may be many more reasons to expect certain populations and categories of people to be more homogeneous or heterogeneous. Theorizing about such explanations and empirically testing hypotheses about varying distributions would be another new direction in comparative sociology. Methods have already been developed for carrying out such an "inverted" multilevel analysis for grouplevel outcomes (Croon and van Veldhoven 2007). 
The small number of studies presented here not only demonstrate that the combination of individual-, regional-, and country-level explanations offers greater explanatory power, but also that differences in orientations are determined (sometimes to a large extent) by differences in countries' composition of these individual characteristics. When studying the impact of macro- and meso-level characteristics on value orientations, the advice of Wil Arts (2011, p. 15) to "always control for the composition of the population by including individual-level variables" should be taken seriously.

Open Access This article is distributed under the terms of the Creative Commons Attribution 4.0 International License (http://creativecommons.org/licenses/by/4.0/), which permits unrestricted use, distribution, and reproduction in any medium, provided you give appropriate credit to the original author(s) and the source, provide a link to the Creative Commons license, and indicate if changes were made.

\section{References}

Alesina, Alberto, and Eliana La Ferrara. 2002. Who trusts others? Journal of Public Economics 85:207-234.

Almond, Gabriel, and Sidney Verba. 1965. The civic culture. Boston: Little, Brown \& Company.

André, Stéphanie, Maurice Gesthuizen and Peer Scheepers. 2013. Support for traditional female roles across 32 countries: Female labour market participation, policy models and gender differences. Comparative Sociology 12:447-476.

Arts, Wil. 2011. Explaining European value patterns: Problems and solutions. Studia UBB Sociologica 56:7-31.

Barnes, Samuel, and Max Kaase. 1979. Political action: Mass participation in five western democracies. Beverly Hills, CA: Sage.

Beugelsdijk, Sjoerd, and Mariko Klasing. 2016. Diversity and trust: The role of shared values. Journal of Comparative Economics 44:522-540.

Chambers, Deborah. 2012. A sociology of family life. Cambridge, Malden: Polity Press.

Coleman, James. 1990. Foundations of social theory. Cambridge, MA: Belknap Press of Harvard University Press.

Croon, Marcel, and Marc van Veldhoven. 2007. Predicting group-level outcome variables from variables measured at the individual level: A latent variable multilevel model. Psychological Methods $12: 45-57$.

Davie, Grace. 1994. Religion in Britain since 1945. Oxford: Blackwell.

De Moor, Ruud. 1994. Epilogue. In The individualizing society, eds. Peter Ester, Loek Halman and Ruud de Moor, 229-232. Tilburg: Tilburg University Press.

De Moor, Ruud. 1987. Religieuze en morele waarden [Religious and moral values]. In Traditie, secularisatie en individualisering, eds. Loek Halman, Felix Heunks, Ruud de Moor and Harry Zanders, 15-49. Tilburg: Tilburg University Press.

Diez-Roux, Ana. 2002. A glossary for multilevel analysis. Journal of Epidemiology and Community Health 56:588-594.

Dotti Sani, Giulia, and Mario Quaranta. 2017. The best is yet to come? Attitudes toward gender roles among adolescents in 36 countries. Sex Roles 77:30-45.

Durkheim, Émile. 1964. The division of labour in society. 1893. New York: Free Press

Durkheim, Émile. 2001. The elementary forms of religious life.1912. Oxford: Oxford University Press.

Eisenstadt, Shmuel. 2002. Some observations on multiple modernities. In Reflections on Multiple Modernities, eds. Dominic Sachsenmaier, Jens Riedel and Shmuel Eisenstadt, 27-41. Leiden, Boston, Cologne: Brill.

Esser, Ingrid, and Arvid Lindh. 2018. Job preferences in comparative perspective 1989-2015: A multidimensional evaluation of individual and contextual influences. International Journal of Sociology 48:142-169.

European Commission. 2017. Special eurobarometer 465 gender equality 2017. Brussels: European Union. European Commission. 2018. Report on equality between women and men in the EU. Luxembourg: Publications Office of the European Union.

European Foundation for the Improvement of Living and Working Conditions. 2004. Quality of Life in Europe. First European Quality of Life Survey 2003. Luxembourg: Office for Official Publications of the 
European Communities, available from: http://www.eurofound.eu.int/publications/files/EF04105EN. pdf.

Finke, Roger, and Amy Adamczyk. 2008. Cross-national moral beliefs: The influence of national religious context. The Sociological Quarterly 49:617-652.

Fox, John. 2016. Applied regression analysis \& Generalized linear models. Third Edition. Thousand Oaks, CA: Sage Publications.

Fukuyama, Francis. 1995. Trust. The social virtues and the creation of prosperity. London: Penguin Books. Genov, Nikolai. 2015. Challenges of Individualisation. International Social Science Journal 64:197-209.

Gesthuizen, Maurice, and Ellen Verbakel. 2011. Job preferences in Europe: Tests for equivalence and explanations for cross-national variation. European Societies 13:663-686.

Grim, Brian, and Roger Finke. 2006. International religion indexes: Government regulation, government favoritism, and social regulation of religion. Interdisciplinary Journal of Research on Religion $2: 1-40$.

Grunow, Daniela. 2019. Comparative analyses of housework and its relation to paid work: Institutional contexts and individual agency. In Cross-national comparative research-analytical strategies, results and explanations. Sonderheft Kölner Zeitschrift für Soziologie und Sozialpsychologie. Eds. Hans-Jürgen Andreß, Detlef Fetchenhauer and Heiner Meulemann. Wiesbaden: Springer VS. https://doi.org/ 10.1007/s11577-019-00608-8.

Gundelach, Peter. 1994. National value differences. Modernization or Institutionalization? International Journal of Comparative Sociology 35:37-58.

Halman, Loek. 1991. Waarden in de Westerse wereld [Values in the Western world]. Tilburg: Tilburg University Press.

Halman, Loek. 2007. Political values. In The Oxford handbook of political behaviour, eds. Russell Dalton and Hans-Dieter Klingemann, 305-322. Oxford: Oxford University Press.

Halman, Loek, and Ruud de Moor. 1987. Waarden: een inleiding [Values: an introduction]. In Traditie, secularisatie en individualisering, eds. Loek Halman, Felix Heunks, Ruud de Moor and Harry Zanders, 1-14. Tilburg: Tilburg University Press.

Halman, Loek, and Ruud de Moor. 1994. Comparative research on values. In The Individualizing Society, eds. Peter Ester, Loek Halman and Ruud de Moor, 21-36. Tilburg: Tilburg University Press.

Halman, Loek, and Astrid Vloet. 1994. Measuring and comparing values in 16 countries of the western world in 1990 and 1981. Tilburg: WORC.

Halman, Loek, Ronald Inglehart, Jaime Díez-Medrano, Ruud Luijkx, Alejandro Moreno and Miguel Basáñez. 2008. Changing values and beliefs in 85 countries. Leiden: Brill.

Halman, Loek, Inge Sieben and Marga van Zundert. 2011. Atlas of European values. Trends and traditions at the turn of the century. Leiden: Brill.

Hank, Karsten, and Anja Steinbach. 2019. Families and their institutional contexts: The role of family policies and legal regulations. In Cross-national comparative research-analytical strategies, results and explanations. Sonderheft Kölner Zeitschrift für Soziologie und Sozialpsychologie. Eds. HansJürgen Andreß, Detlef Fetchenhauer and Heiner Meulemann. Wiesbaden: Springer VS. https://doi. org/10.1007/s11577-019-00608-8.

Hirschle, Jochen. 2013. "Secularization of Consciousness" or alternative opportunities? The impact of economic growth on religious belief and practice in 13 European countries. Journal for the Scientific Study of Religion 52:410-424.

Hooghe, Marc, Tim Reeskens, Dietlind Stolle and Ann Trappers. 2009. Ethnic diversity and generalized trust in Europe. Comparative Political Studies 42:198-223.

Hox, Joop, Mirjam Moerbeek and Rens van de Schoot. 2017. Multilevel analysis: Techniques and applications. Third Edition. London \& New York: Routledge.

Inglehart, Ronald 1977. The silent revolution. Princeton, NJ: Princeton University Press.

Inglehart, Ronald 1997. Modernisation and postmodernisation. Princeton, NJ: Princeton University Press.

Inglehart, Ronald 2018. Modernisation, Existential security and cultural change: Reshaping human motivations and society. In Handbook of advances in culture and psychology, volume 7, eds. Michele Gelfand, Chi-yue Chiu and Ying-yi Hong. Oxford: Oxford University Press.

Inglehart, Ronald, and Christian Welzel. 2005. Modernisation, cultural change and democracy. Cambridge: Cambridge University Press.

Jutz, Regina, Evi Scholz, Michael Braun and Markus Hadler. 2018. The ISSP 2015 Work Orientations IV Module. International Journal of Sociology 48:95-102.

Kerkhofs, Jan. 1997. De Europeanen en hun waarden [Europeans and their values]. Leuven: Davidsfonds.

Kroneberg, Clemens. 2019. Theory development in comparative social research. In Cross-national comparative research - analytical strategies, results and explanations. Sonderheft Kölner Zeitschrift für 
Soziologie und Sozialpsychologie. Eds. Hans-Jürgen Andreß, Detlef Fetchenhauer and Heiner Meulemann. Wiesbaden: Springer VS. https://doi.org/10.1007/s11577-019-00608-8.

Lerner, Daniel. 1968. Modernisation. In International encyclopedia of the social sciences, eds. David Sills and Robert Merton, 386-395. New York: Macmillan.

Lesthaeghe, Ron 2014. The second demographic transition: A concise overview of its development. PNAS 111:18112-18115.

Letki, Natalia. 2006. Investigating the roots of civic morality: Trust, social capital, and institutional performance. Political Behaviour 28:305-325.

Marsh, Robert. 2014. Modernisation theory, then and now. Comparative Sociology 13:261-283.

Mead, George Herbert. 1934. Mind, self, and society: From the standpoint of a social behaviourist. Chicago: University of Chicago Press.

Meulemann, Heiner 1983. Value change in West Germany, 1950-1980: Integrating the empirical evidence. Social Science Information 22:777-800.

MOW International Research Team. 1987. The meaning of working. New York: Academic Press.

Naldini, Manuela, Emmanuele Pavolini and Christina Solera. 2016. Female employment and elderly care: The role of care policies and culture in 21 European countries. Work, Employment and Society 30:607-630.

Norris, Pippa, and Ronald Inglehart. 2004. Sacred and secular. Cambridge: Cambridge University Press.

Olson, Daniel, and Miao Li. 2015. Does a nation's religious composition affect generalized trust? The role of religious heterogeneity and the percent religious. .Journal for the Scientific Study of Religion 54:756-773.

Phillips, David, and Stephen Harding. 1985. The structure of moral values. In Values and social change in Britain, eds. Mark Abrams, David Gerard and Noel Timms, 93-108. London: MacMillan.

Pichler, Florian, and Claire Wallace. 2009. What are the reasons for differences in job satisfaction across Europe? Individual, Compositional, and Institutional Explanations. European Sociological Review 25:535-549.

Preyer, Gerhard, and Michael Sussman. 2016. Introduction on Shmuel N. Eisenstadt's sociology: The path to multiple modernities. In Varieties of multiple modernities. New Research Design, eds. Gerhard Preyer and Michael Sussman, 1-29. Leiden, Boston: Brill.

Przeworski, Adam, and Henry Teune. 1970. The logic of comparative social inquiry. New York: John Wiley \& Sons.

Putnam, Robert. 1993. Making democracy work. Princeton, NJ: Princeton University Press.

Putnam, Robert, and David Campbell. 2010. American grace: How religion divides and Unites Us. New York: Simon and Schuster.

Rapp, Carolin. 2016. Moral opinion polarization and the erosion of trust. Social Science Research 58:34-45.

Robertson, Roland 1992. Globalization. London: Sage

Robinson, William 1950. Ecological correlations and the behaviour of individuals. American Sociological Review 15:351-357.

Sachsenmaier, Dominic. 2002. Multiple modernities. The concept and its potential. In Reflections on multiple modernities, eds. Dominic Sachsenmaier, Jens Riedel and Shmuel Eisenstadt, 42-67. Leiden, Boston, Cologne: Brill.

Schmidt, Volker. 2010. Modernity and diversity: Reflections on the controversy between modernisation theory and multiple modernists. Social Science Information 49:511-538.

Schulz, Wolfram, John Ainley, Julian Fraillon, David Kerr, and Bruno Losito. 2010. ICCS 2009 International report: Civic knowledge, attitudes, and engagement among lower-secondary school students in 38 countries. Amsterdam: International Association for the Evaluation of Educational Achievement (IEA).

Schwadel, Philip. 2015. Explaining cross-national variation in the effect of higher education on religiosity. Journal for the Scientific Study of Religion 54:402-418.

Sieben, Inge, and Loek Halman. 2015. Morality on the public good in post-socialist European states. Studies of Transition States and Societies 7:7-26.

Siegers, Pascal. 2019. Is the influence of religiosity on attitudes an behaviors stronger in less religious or more religious societies? A review of theories ana contradictory. In Cross-national comparative research - analytical strategies, results and explanations. Sonderheft Kölner Zeitschrift für Soziologie und Sozialpsychologie. Eds. Hans-Jürgen Andreß, Detlef Fetchenhauer and Heiner Meulemann. Wiesbaden: Springer VS. https://doi.org/10.1007/s11577-019-00608-8.

Smelser, Neil 1973. Toward a theory of modernisation. In Social change, sources, patterns, and consequences, eds. Eva Etzioni-Halevy and Amitai Etzioni, 268-284. New York: Basic Books. 
Stoetzel, Jean. 1983. Les Valeurs du temps présent: Une enquête Européenne. [Today's values. A European survey] Paris: Presses Universitaires de France.

Storm, Ingrid. 2016. Morality in context: A multilevel analysis of the relationship between religion and values in Europe. Politics and Religion 9:111-138.

Storm, Ingrid. 2017. Does economic insecurity predict religiosity? Evidence from the European social survey 2002-2014. Sociology of Religion: A Quarterly Review 78:146-172.

Te Grotenhuis, Manfred, Marijn Scholte, Nan-Dirk de Graaf and Ben Pelzer. 2015. The between and within effects of social security on church attendance in Europe 1980-1998: The danger of testing hypotheses cross-nationally. European Sociological Review 31:643-654.

Van Deth, Jan. 1995. Introduction: The impact of values. In The impact of values, eds. Jan van Deth and Elinor Scarbrough, 1-18. Oxford: Oxford University Press.

Van Deth, Jan, and Kent Jennings. 1989. Introduction. In Continuities in political action eds. Jan van Deth and Kent Jennings, 3-21. Berlin, New York: Walter de Gruyter.

Van Deth, Jan, and Elinor Scarbrough. 1995. The impact of values. Oxford: Oxford University Press.

Voicu, Mălina, and Andreea Constantin. 2014. Attitudes towards gender roles in Europe: Modernisation and social institutions. In Value contrasts and consensus in present-day Europe, eds. Wil Arts and Loek Halman, 311-328. Leiden, Boston: Brill.

Zanders, Harry. 1994. Changing work values. In The individualizing society, eds. Peter Ester, Loek Halman and Ruud de Moor, 129-154. Tilburg: Tilburg University Press.

Loek Halman 1956, PhD., Associate Professor at Tilburg University. Areas of research: Values, comparative studies, sociology. Publications: The Atlas of European Values, Leiden, 2011 (with I. Sieben and M. van Zundert); Religion and Civil Society, Dordrecht, 2013 (ed. with J. de Hart and P. Dekker); Value Contrasts and Consensus in Present-Day Europe, Leiden (ed. with W. Arts).

John Gelissen 1972, PhD., Endowed Professor at Tilburg University. Areas of research: Sociological and methodological research on cross-cultural differences in public opinion. Publications: Testing Measurement Equivalence of Experienced Holiday Quality: Evidence on Built-in Bias in the Flash Eurobarometer survey data, 2018; Clusters of cultures: Diversity in meaning of family value and gender role items across Europe, 2017 (with E. van Vlimmeren and G. Moors); Exploring the response process of culturally differing survey respondents with a response style: A sequential mixed methods study, 2013 (with M. Morren and J.K. Vermunt). 